\title{
Building Knowledge: Giving a New Meaning to the Teaching of Chemistry in Everyday School Life
}

\author{
Rita de Cássia Costa Modesto, Carolina Candida de Paula Souza, \\ Marcio Antonio Ferreira Camargo, Carmen Aparecida Cardoso Maia Camargo \\ University of State of Minas Gerais, Academic unit of Passos, Minas Gerais, Brazil \\ Email: ritadecassiacosta18@outlook.com, carolinacandaps@gmail.com,marcio.camargo@uemg.br, carmen.camargo@uemg.br
}

How to cite this paper: de Cássia Costa Modesto, R., de Paula Souza, C.C., Camargo, M.A.F. and Camargo, C.A.C.M. (2021) Building Knowledge: Giving a New Meaning to the Teaching of Chemistry in Everyday School Life. Open Access Library Journal, 8: e7271.

https://doi.org/10.4236/oalib.1107271

Received: March 1, 2021

Accepted: March 28, 2021

Published: March 31, 2021

Copyright $\odot 2021$ by author(s) and Open Access Library Inc.

This work is licensed under the Creative Commons Attribution International License (CC BY 4.0).

http://creativecommons.org/licenses/by/4.0/

\section{(c) (i) Open Access}

\begin{abstract}
This work was developed from an Extension Project developed in the 1st year of High School, in Public Schools located in the municipality of Passos, Minas Gerais. The project aimed to assist teachers and students of the 1st year of high school in learning the discipline of Chemistry and show that the performance of experimental and playful activities help to bring the chemistry seen in the classroom to the students' daily lives, thus making more dynamic classes. For this, the project proposed a participatory teaching methodology, through pedagogical workshops on the theoretical contents, taught in the classroom, that is, a creative and constructive teaching practice of Chemistry, different from the traditional pedagogy that values verbalization and transmission of theoretical content, decontextualized knowledge and memorization of formulas. After the practices, a questionnaire with closed questions was used to evaluate the workshops developed. The project was carried out in three public schools, focusing on acid and base themes and chemical reactions. The workshops were held between August and October 2019, four workshops were held in each school, totaling 114 students. From the activities carried out, it was possible to conclude that, the students are able to identify and assimilate the chemical contents in a playful and participatory way, arousing the curiosity for the Teaching of Chemistry.
\end{abstract}

\section{Subject Areas \\ Education, Teaching of Chemistry}

\section{Keywords}

Chemistry Teaching, School Daily Life, Utilitarian Chemistry 


\section{Introduction}

In the school routine, practical classes have a great influence on the teaching-learning process. The way in which Chemistry teaching is approached in schools may have contributed to the spread of distorted conceptions of this science, since the concepts are presented in a purely theoretical way, as something that should be memorized and that does not apply to different aspects of everyday life. The Chemistry teaching strategy with practical classes makes it possible to overcome these limitations and awakens the students' interest in teaching Chemistry. The general objective of the extension project was to propose workshops to assist teachers and students of the 1st year of high school in learning the discipline of Chemistry and also to show that the performance of experimental and playful activities helps to bring the chemistry seen in the classroom students' daily lives, thus making classes more dynamic. The project was developed from May 3, 2019 to December 15, 2019, through workshops at Public High Schools in the city of Passos-MG. The proposal of the project is that the practices were developed fortnightly, in the total of four experiments in each school. Each practice has its own theme, developed together with the professor, the discipline's advisor and the fellow responsible for the project. In order to carry out this project, a survey was made of the state schools in the city of Passos-MG that had high school, and were subsequently contacted. In the total of 9 , only 3 of them showed interest in the project after meeting with the direction and teachers of the discipline. Within the needs pointed out by the teachers of the discipline, four experiments were chosen, on acids and bases and chemical reactions. The workshops were concluded in October. The innovative practices of Chemistry have made it possible to learn the concepts worked on and their importance in the study of the reality of the contemporary world.

Considering that the teaching of Chemistry practiced in a large number of schools, is far from what is proposed by the new methodologies in the Teaching of Natural Sciences, it is necessary that innovative and practical methodologies be implemented in the classroom, arousing curiosity and interest of the student, aiming at quality education.

Quality teaching must promote meanings to the student, according to Moreira [1], in this context it is possible to see the importance of practical classes in the teaching of Chemistry. In the school routine, students are uninterested in chemistry, claiming their difficulty and the apparent lack of application in their daily lives. This scenario is transformed when playful forms of reproduction are presented to these students.

The possibility of experimenting with diverse didactic forms has a significant impact on the teaching-learning process, causing them to set aside just memorizing, facilitating the understanding and fixation of the contents, which, in the end, is the intention of those who pass on this information. For learning to occur, according to Kollock [2], two barriers must be overcome, motivation and coordination. Motivated students can develop a critical spirit in observing che- 
mistry in everyday life, according to Queiroz [3] that knowledge is not finished and ready, but produced in a social and historical context. Therefore, science, in this perspective, deconstructs the view of neutrality and impartiality of its results and inferences.

Enabling the student to stop being just a listener and start to carry out experiments is undoubtedly an instrument of great value within the ways of building scientific knowledge.

This project started from the principle that bringing students closer to chemistry, through educational practices, allows the opportunity to expand their knowledge and understand the relationship between content applied in the classroom and what happens outside it, in their daily lives. In order to achieve these objectives, the structuring concepts of the sciences were guided, those that allow impetus using new methods and new instruments.

The general objective of the project was to assist teachers and students of the 1st year of high school in learning the discipline of Chemistry and also to show that the performance of experimental and playful activities helps to bring the teaching of Chemistry seen in the classroom and applicability in students' daily lives, thus making classes more dynamic.

\section{Materials and Methods}

Offering practical, innovative and contextualized classes, makes the world of science and the student's everyday world narrower, enabling bridges between the content taught and the universe of the student, so it is a strategy that can be applied in the teaching of chemistry.

According to Nardi [4], the reasons characterized by teachers for the deficit in practical teaching of chemistry are diverse, therefore, it is important to work on continuing education in which teaching does not mean merely transferring knowledge, but creating new ways for student learning is achieved. In this sense, practical and laboratory activities are important, as they combine theory and practice. Taking into account that the lack of laboratories is a reality in Brazilian schools, it is necessary, practical activities in which alternative materials can be used.

A qualitative and participatory methodological approach was used, since the extension worker was part of the project, elaborating and participating in the practices carried out and not just observing and noting.

The main objective of this project was to offer practical classes to schools in which they were not applied, in this context some of the problems reported by teachers in the difficulty in administering the practice were overturned. Because the material was offered, people trained for the classes to be taught and in order to facilitate the understanding of the student so that he could be putting aside the idea of outdated chemistry that only works in the classroom in a decorated way. Enabling an environment that allowed to discuss results and concepts.

The activities were carried out in state schools that have high school in the city 
of Passos, municipality of Minas Gerais. A survey was made of schools that teach practical chemistry classes and have a laboratory. The schools were named in alphabetical order from A to I, for reasons of confidentiality, as shown in Table 1.

The city of Passos has nine state public schools that have high school, and three of them have practical classes. After the survey, schools were offered participation in the project and workshops for practical classes. Of the total, only three schools were chosen, using as a criterion of choice the absence of practical classes and the availability of teachers of the discipline to participate in the project. After choosing the schools, a meeting was held with the teachers of the subjects in each school so that the content and needs to be worked out were guided. At the end of the pedagogical workshops, a questionnaire was applied to the students to evaluate the content and the Project.

\section{Results and Analysis}

The project's workshops started in August and ended in October, totaling 114 students served by this project, in a total of four practical classes in each school. Among the needs pointed out by the teachers, four experiments were chosen, which dealt with the following themes: acids and bases and chemical reactions.

\subsection{Ink that Disappears Materials}

2 beakers, distilled water, ethyl alcohol, ammonium hydroxide, spoon of phenolphthalein indicator sugar. The phenolphthalein was dissolved in alcohol with stirring. Then, this solution was added to the ammonium hydroxide, the solution turned red due to the phenolphthalein indicator in solution, being in the $\mathrm{pH}$ range between 8.2 to 10.0 , this mixture was sprayed on a white handkerchief, making-the red, after evaporation to air, the ammonia gas $\left(\mathrm{NH}_{3}\right)$ was released, becoming a white scarf again, as shown in Figure 1.

Table 1. Survey of practical classes and laboratory.

\begin{tabular}{ccc}
\hline Schools & Practices Classes & Laboratory \\
\hline A & No & No \\
B & No & No \\
C & Yes & No \\
D & No & Yes \\
E & Yes & Yes \\
F & Yes & Yes \\
G & No & No \\
H & No & No \\
I & No & No \\
\hline
\end{tabular}

Source: Author (2019). 


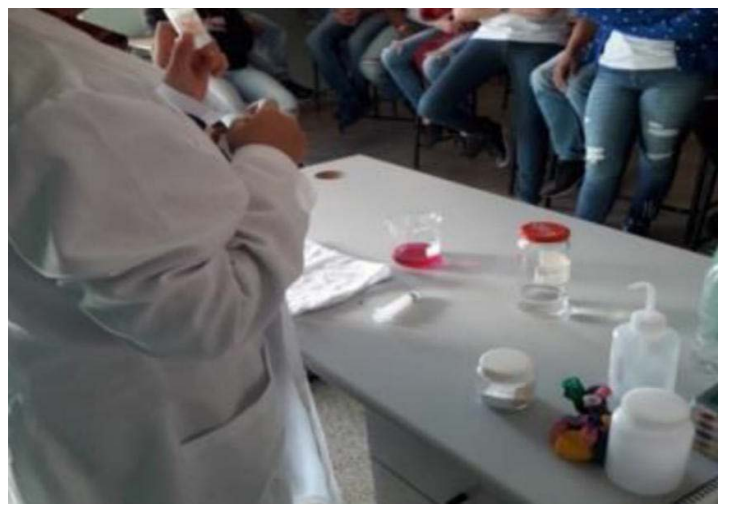

Figure 1. Ink that disappears. Source: Author (2019).

\section{Chemical reaction that occurs:}

$$
\mathrm{NH}_{4}^{+}(\mathrm{aq})+\mathrm{OH}^{-}(\mathrm{aq}) \rightleftharpoons \mathrm{NH}_{3}(\mathrm{~g})+\mathrm{H}_{2} \mathrm{O}(\mathrm{l})
$$

\subsection{Balloon}

Materials: PET bottles, balloons, baking soda, vinegar.

$50 \mathrm{~mL}$ of vinegar were placed in PET bottles. Then, a tablespoon of baking soda was added into the flasks. The mouth of the flask was fixed on the neck of the bottles so that the sodium bicarbonate could be transferred to the inside of the flask, causing a chemical reaction that, when loosing the carbon dioxide $\left(\mathrm{CO}_{2}\right)$ gas, caused the filling of the flasks instantly, as shown in Figure 2.

\section{Chemical reaction that occurs:}

$$
\mathrm{CH}_{3} \mathrm{COOH}(\mathrm{aq})+\mathrm{NaHCO}_{3}(\mathrm{aq}) \rightarrow \mathrm{CH}_{3} \mathrm{COONa}(\mathrm{s})+\mathrm{H}_{2} \mathrm{O}(\mathrm{l})+\mathrm{CO}_{2}(\mathrm{~g})
$$

\subsection{Blow-Activated Chemical Reaction}

Materials: Straws, bromothymol blue acid-base indicator, ethyl alcohol, Erlenmeyer, $\mathrm{NaOH} 1 \mathrm{~mol} / \mathrm{L}$

In the conical flask, alcohol and 4 drops of the bromothymol blue acid-base indicator were added. Then, a drop of sodium hydroxide solution $(\mathrm{NaOH})$ was added. The solution obtained showed a bluish color and with the help of a straw, it was blown into the container containing the solution, it was observed that the solution changed from blue (basic $\mathrm{pH}$ ) to yellow (acid $\mathrm{pH}$ ) and then to green (neutral pH), as shown in Figure 3.

\section{Chemical reactions that occur:}

$$
\begin{gathered}
\mathrm{CO}_{2}(\mathrm{~g})+\mathrm{H}_{2} \mathrm{O}(\mathrm{l}) \rightarrow \mathrm{H}_{2} \mathrm{CO}_{3}(\mathrm{aq}) \\
\mathrm{H}_{2} \mathrm{CO}_{3}(\mathrm{aq})+\mathrm{NaOH}(\mathrm{aq}) \rightarrow \mathrm{NaHCO}_{3}(\mathrm{aq})+\mathrm{H}_{2} \mathrm{O}(\mathrm{l})
\end{gathered}
$$

\subsection{Acid Rain}

Materials: glass with lid, alcoholic solution of phenolphthalein acid-base indicator, copper wire, litmus paper, red flower petal (hibiscus), sulfur powder, candle, aluminum foil, teaspoon. 


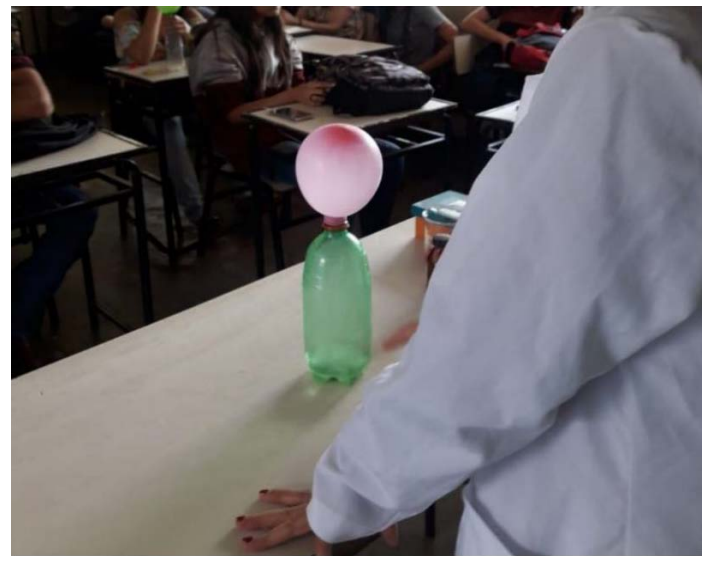

Figure 2. Balloon. Source: Author (2019).

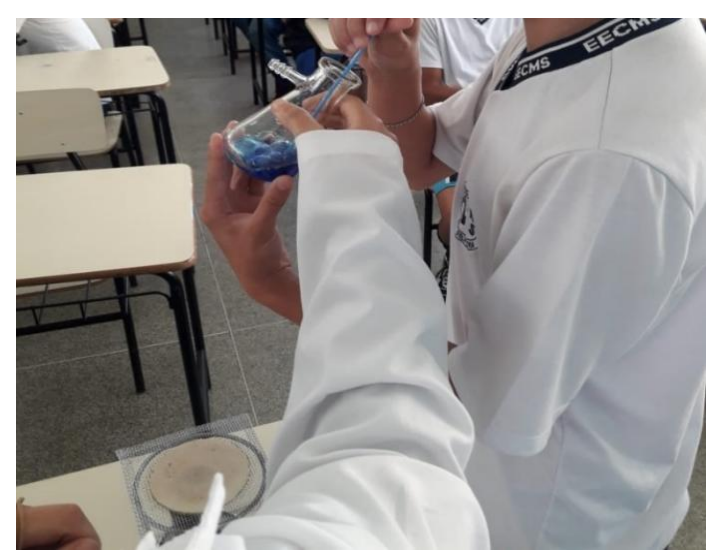

Figure 3. Blow-activated chemical reaction. Source: Author (2019).

Two small holes were made in the glass cover so that the copper wire could pass through, the aluminum foil was folded so that it was similar to a spoon, fastening right after the wire next to the cover, a teaspoon of powdered sulfur. The petals and litmus paper were accommodated inside the glass. The candle was used to cause the combustion of sulfur in the spoon, as soon as combustion happened, the lid was placed on the glass. The formation of a white mist was observed and after a few minutes, there were changes in the blue to red colors of litmus paper, characterizing the change in $\mathrm{pH}$ from basic to acid, with a change in the appearance of the flower petals, as shown in Figure 4.

\section{Chemical reactions that occur:}

$$
\begin{gathered}
\mathrm{S}(\mathrm{s})+\mathrm{O}_{2}(\mathrm{~g}) \rightarrow \mathrm{SO}_{2}(\mathrm{~g}) \\
\mathrm{SO}_{2}(\mathrm{~g})+1 / 2 \mathrm{O}_{2}(\mathrm{~g}) \rightarrow \mathrm{SO}_{3}(\mathrm{~g}) \\
\mathrm{SO}_{3}(\mathrm{~g})+\mathrm{H}_{2} \mathrm{O}(\mathrm{l}) \rightarrow \mathrm{H}_{2} \mathrm{SO}_{4}(\mathrm{l})
\end{gathered}
$$

Through simple experiments the relationship between theory and practice of the content was worked, so that little by little the students would be interested in Chemistry and simultaneously making connections with everyday life. 


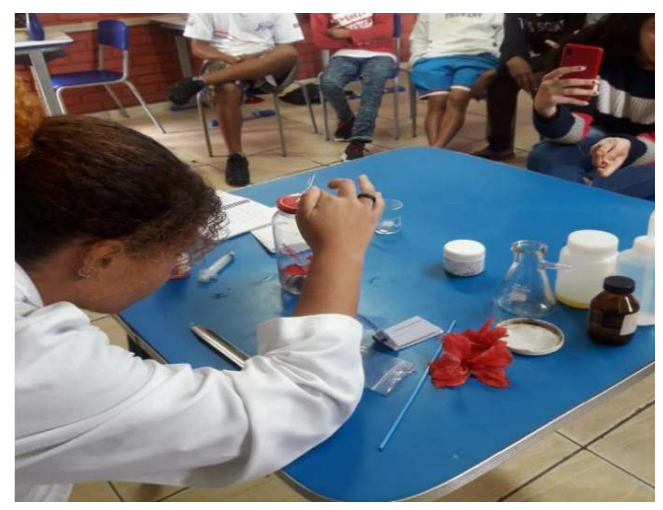

Figure 4. Acid rain. Source: Author (2019).

The students improved the concepts of chemical reactions, acids and bases, after the experimental class, it was possible to observe a significant increase in the students' curiosity/interactivity.

\subsection{Quiz}

After completing the practical activities, a questionnaire was prepared and applied to the students, with seven objective questions, to verify the fixation of the contents worked on in the practices and a question about the use of the classes, as shown in Figure 5.

\section{Discussion}

Based on Figure 5 presented together with the related questions (Appendix) it is possible to see that these students were able to make associations with their daily lives, observing question number one here, it was possible for them to realize that there is more chemistry in their lives than they might think, thus concluding one of the objectives of this project, which is to promote assimilation.

The question with the lowest success rate was number two, which can be analyzed and noticed that these students have a greater difficulty in learning about acids and bases and that has not been completely remedied with the amount of classes offered, which can serve as assistance for teachers to start working better on the educational deficits in the area.

Analyzing the opinions of these students about the practical classes offered, regarding question number eight, it was concluded that 72 of them liked the classes, (about 63\%) and with a good rate of achievement.

Through simple experiments worked the relationship between theory and practice of content, so that little by little the students would be interested in Chemistry and simultaneously making connections with daily life.

The students improved the concepts of acids and bases and chemical reactions, after the experimental class, it was possible to observe a significant increase in the students' curiosity/interactivity. As confronted in the questionnaire, the majority of the participating students showed motivation and interest in the practices developed. 


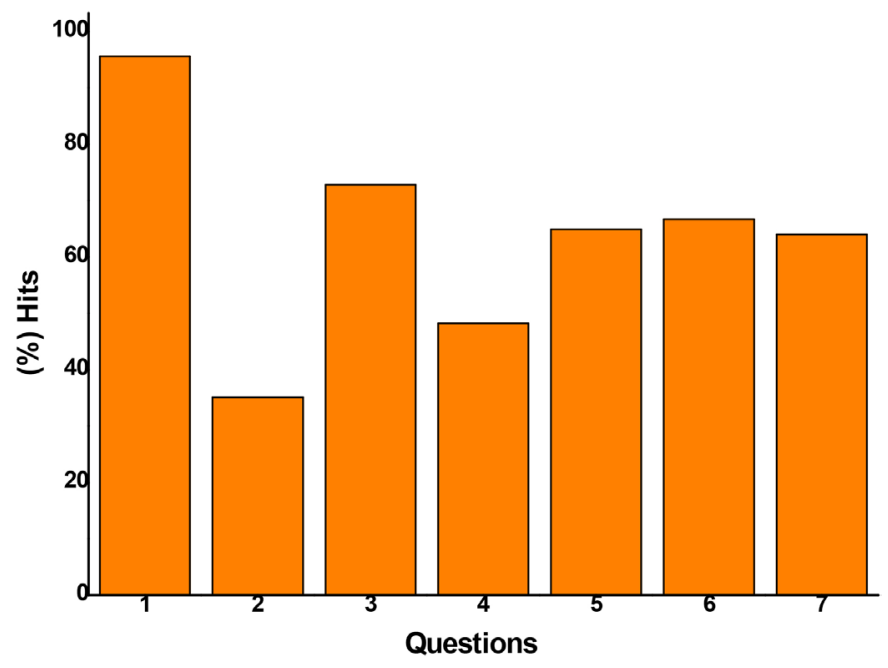

Figure 5. Content evaluation of practical classes workshops. Source: Author (2019).

In addition to enabling the perception of the relationship between the content that occurs in the classroom and experimentation practice. Therefore, it can be said that the innovative and attractive practices related to the teaching of Chemistry arouse in students, the interest and importance of chemical concepts present in school curricula, favoring contextualization, as a strategy for the appropriation of content present in everyday life.

\section{Conclusions}

Assessing the entire context, it can be concluded that meaningful and quality learning is extremely important in the teaching-learning process. By providing dynamic, practical classes and making the student the protagonist of knowledge, skills and abilities necessary for quality teaching are developed.

Encouraging and sharpening curiosity with quality classes, questions arise about the content taught and not just memorization. Thus, it makes possible the appropriation of knowledge, as in the specific case of the project, the knowledge of Chemistry. The learner becomes the protagonist of knowledge and not only supporting it, making scientific learning effective.

Taking into account that the classroom environments do not have only one type of student, with only a certain type of intelligence.

Gardner [5] emphasizes that the ways of receiving and apprehending information are diverse. The practical and dynamic classes favor a democratization of teaching, as it serves diversities. If the focus of the educator is to provide quality education, the use of innovative practices and playful didactics is of great value in education.

Therefore, the use of experimentation in the classroom becomes a pedagogical alternative, aiming at the interaction of students in the teaching and learning process, given the understanding of the contents in a meaningful way involving the mediation of the teacher. 
The project was of great relevance for the academic training of extension workers, enabling the experience of innovative practices in the area of Natural Sciences, specifically in the discipline of Chemistry. It provided the opportunity to arouse interest in quality teaching, addressing a renewed stance on the conception of knowledge, which allows understanding the nature of the teaching-learning process.

\section{Acknowledgements}

To the State University of Minas Gerais UEMG/PAEx, for the scholarship granted.

\section{Conflicts of Interest}

The authors declare no conflicts of interest regarding the publication of this paper.

\section{References}

[1] Masini, E.A.F. and Moreira, M.A. (2008) Aprendizagem significativa: Condições para ocorrência e lacunas que levam a comprometimentos. Vetor Editora Psico-Pedagógica, São Paulo, 296 p.

[2] Kollock, P. (1999) The Economies of on Line Cooperation: Gifts and Public Goods in Cyberspace. In: Smith, M.A. and Kollock, P., Eds., Communities in Cyberspace. Routledge, London, 220-242.

[3] Queiroz, M.M.A. (2006) Projeto escola ativa: Os desafios de ensinar ciências naturais em classes multisseriadas da zona rural de Teresina-Piauí. 2006. 194 f. Dissertação (Mestrado em Educação), Universidade Federal do Piauí, Teresina.

[4] Nardi, R. (2013) Questões atuais no ensino de ciências. Escrituras, São Paulo.

[5] Gardner, H. (2000) Inteligência: Um conceito reformulado. Objetiva, Rio de Janeiro. 


\section{Appendix}

Evaluation of content taught in practical classes

Project: Building knowledge: giving a new meaning to the teaching of Chemistry in everyday school life

School:

Date:

Answer the questions below according to the content of the practical classes

1) Chemical reactions are the result of actions between substances that generally form other substances. Based on this statement, give examples of chemical reactions that are present in your daily life.

2) In the first experiment (paint that disappears) we witnessed a rapid color change when a few drops of phenolphthalein were added to the mixture of ammonium hydroxide and water. What is the reason for this reaction to occur?

3) Based on the experiment with the flask, vinegar and bicarbonate answer: what happens when the acetic acid (vinegar) comes into contact with $\mathrm{NaHCO}_{3}$ (sodium bicarbonate)? Is any other substance formed? If so, what substance is that?

4) Answer according to the third experiment (chemical reaction activated by voice).

When we speak, we eject a large amount of $\mathrm{CO}_{2}$, which in contact with water turns into carbonic acid. What does this carbonic acid do with the base $\mathrm{NaOH}$, sodium hydroxide) that we use?

5) Respond based on the acid rain experiment.

When sulfur burns, it reacts with oxygen in the air giving rise to another substance, what is it called?

6) What are the harms of acid rain for the environment?

7) There is a unit of measurement that describes the degree of acidity or alkalinity of a substance. What is it called? 